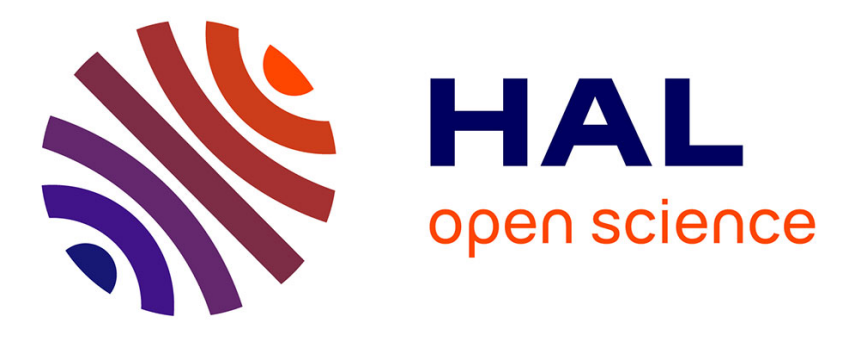

\title{
Super resolution spectroscopy for THz-TDS: application to gas spectroscopy
}

\author{
Sophie Eliet, Meriem Mouelhi, A. Cuisset, Francis Hindle, Jean-Francois \\ Lampin, Romain Peretti
}

\section{To cite this version:}

Sophie Eliet, Meriem Mouelhi, A. Cuisset, Francis Hindle, Jean-Francois Lampin, et al.. Super resolution spectroscopy for THz-TDS: application to gas spectroscopy. 45th International Conference on Infrared, Millimeter, and Terahertz Waves (IRMMW-THz), Nov 2020, Buffalo, NY (virtual), United States. pp.1-2, 10.1109/IRMMW-THz46771.2020.9370802 . hal-03191457

\section{HAL Id: hal-03191457 \\ https://hal.science/hal-03191457}

Submitted on 4 Aug 2021

HAL is a multi-disciplinary open access archive for the deposit and dissemination of scientific research documents, whether they are published or not. The documents may come from teaching and research institutions in France or abroad, or from public or private research centers.
L'archive ouverte pluridisciplinaire HAL, est destinée au dépôt et à la diffusion de documents scientifiques de niveau recherche, publiés ou non, émanant des établissements d'enseignement et de recherche français ou étrangers, des laboratoires publics ou privés. 


\title{
Super resolution spectroscopy for THz-TDS: Application to Gas spectroscopy
}

\author{
S. Eliet ${ }^{1}$, M. Mouelhi ${ }^{2}$, A.Cuisset ${ }^{2}$, F.Hindle ${ }^{2}$, J.-F. Lampin ${ }^{1}$ and R. Peretti ${ }^{1}$, \\ ${ }^{1}$ Univ. Lille, CNRS, Centrale Lille, Univ. Polytechnique Hauts-de-France, UMR 8520 - IEMN, F-59000 Lille, \\ France, \\ ${ }^{2}$ Laboratoire de Physico-Chimie de l'Atmosphère, Université du Littoral Côte d'Opale, Dunkerque, France,
}

\begin{abstract}
Time Domain Spectroscopy resolution is usually limited by the Fourier Heisenberg criteria (FHC) coming from the length of the delay line. We will present a method to exploit THz-TDS spectra providing a $\sim 10$-fold resolution improvement reaching $\sim 120 \mathrm{MHz}$ for width measurements. These results were obtained by modeling and the implementation of a constraint reconstruction algorithm. We tested the methods on temporal traces from gaseous $\mathrm{NH}_{3}$ and were in very good agreement with the values from literature [1] down to a pressure of 5 mbar.
\end{abstract}

\section{INTRODUCTION}

$\mathrm{S}$ UPER-RESOLUTION refers to a class of techniques that enhances the resolution of an apparatus beyond a theoretical limitation. It appeared first in signal processing where a time window limited the resolution, and made recent breakthroughs in microscopy. There, the super-resolution microscopy imaging techniques overcame the diffraction limit and their consequences in biology related fields lead to the 2014 Nobel Prize for chemistry.

THz Time-Domain Spectroscopy (THz-TDS) is a technique recording in a single experiment a very broad spectrum (from $200 \mathrm{GHz}$ to $6 \mathrm{THz}$ for commercial apparatus and up to $70 \mathrm{THz}$ with lab experiments) including a lot of information. Its resolution comes from the FHC arising from the relatively short range of the delay line and is typically around $1 \mathrm{GHz}$ $(1.2 \mathrm{GHz}$ in our case). Such a resolution is good enough for myriad of uses from fundamental physics to industrial applications. Still, several kinds of samples such as high Q photonic resonators and gas samples are out of reach of TDS performances. However, getting such a broadband spectrum would be very efficient for multicomponent gas phase analysis, even in realistic media containing aerosols [2]. However, the limited spectral resolution does not allow the narrow lines of the gas fingerprint to be fully resolved.

We will present a super-resolution method dedicated to $\mathrm{THz}$ -TDS. First, we will give theoretical insight and numerical examples before applying our methods and software to time traces from gaseous $\mathrm{NH}_{3}$ from atmospheric pressure down to few mbars.

\section{RESULtS}

One of the most important difference between superresolution in spectroscopy and microscopy is that if the shape of an object can be arbitrary in microscopy, the shape of a spectroscopic line is much more constrained. Concretely, the collisional broadened rotational lines of a gas follow a Lorentzian profile in the frequency domain, corresponding to an exponentially damped sinus in the time domain. Each line of the spectrum needs only three parameters to be described: their central frequency, their width and their intensity. These line shape parameterization combined to the precise knowledge of the repetition rate of the laser in the TDS system enables to reconstruct the sample time trace from a reference one.

We tested the method on fictitious samples including noises and we retrieved the values of the line parameters and even the beating frequency of a doublet (two lines closer than the FHC) with a very good precision depending only on the signal to

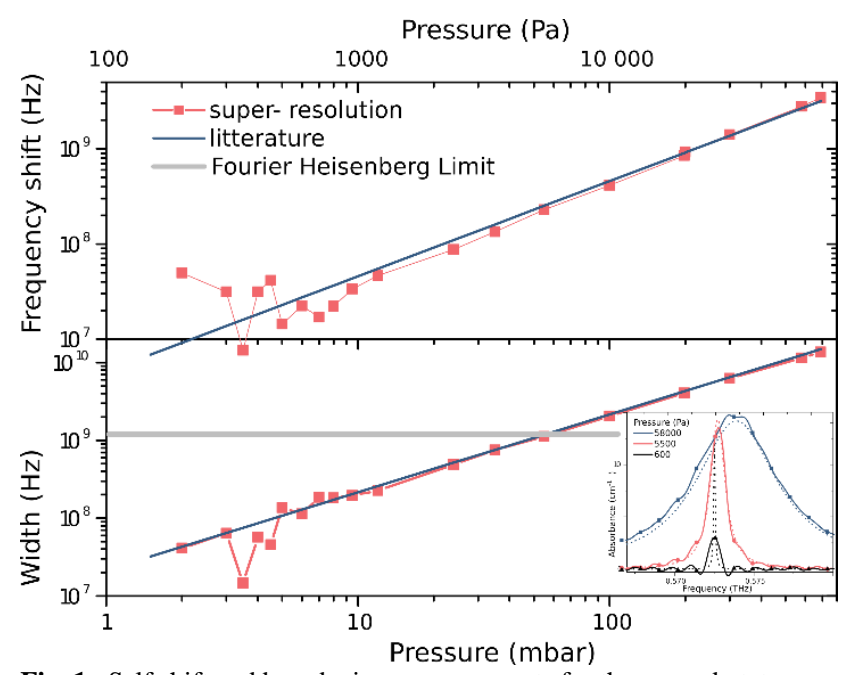

Fig. 1. Self shift and broadening measurements for the ground-state rotational transition $\mathrm{s}(1,0) \leftarrow \mathrm{a}(0,0)$ of $\mathrm{NH} 3$ around $572 \mathrm{GHz}$. Top: absolute central frequency shift versus pressure of the line (The frequency at null pressure is taken from [1]) compare to the literature value from the same database. Bottom: linewidth of the same line versus pressure compare to the value of the same database. Inset: three examples of spectrum at 6,55 and 580 mbar. Square, data from FFT of the time-traces. continuous line. data from zero padded time traces.

noise ratio. Then, we used this method on experimental time traces from gaseous $\mathrm{NH}_{3}$ samples and plotted the result on fig1. Here the experimental data follows the literature one with a precision of few tens of $\mathrm{MHz}$ for the line frequency pressure shift and $\pm 10 \%$ precision for the line self broadening, down to $\mathrm{P}=500 \mathrm{~Pa}$ (meaning a width of $\sim 100 \mathrm{MHz}$ ) for the rotational line centered at $572 \mathrm{GHz}$. The six parameters of the line doublet at $1.21 \mathrm{THz}$ (separated by $\sim 400 \mathrm{MHz}$ ) were retrieved down to $\mathrm{P}=2400 \mathrm{~Pa}$ because it requires more information meaning a higher signal to noise ratio and thus more absorption.

We anticipate the proposed method to be widely used to enhance the performances of TDS systems expanding its use in other fields such as gas spectroscopy.

\section{REFERENCES}

[1] S.P. Belov et al. "Study of Microwave Pressure Lineshifts": Dynamic and Isotopic Dependences", Journal of Molecular Structure 101, 258-270 (1983) 
[2] D.Bigourd et al. "Multiple component analysis of cigarette smoke using THz spectroscopy, comparison with standard chemical analytical methods", Appl.Phys.B. vol 86, pages579-586( (2006). 